\title{
Lo alegórico y el rastro: acerca de la inscripción de la temporalidad en Ursprung des deutschen Trauerspiel y el Passagen-Werk
}

\author{
María Castel - UBA
}

Resumen: La simetría del estudio benjaminiano sobre el Drama Barroco y su proyecto historiográfico en torno a los Pasajes de París, aparece documentada en numerosas piezas de su correspondencia personal. Queremos aquí proponer una analogía que Benjamin no ha explicitado: así como en el libro sobre el Drama Barroco las categorías de análisis fundamentales son las figuras estéticas del símbolo y la alegoría -y si bien estas categorías perviven en el Libro de los Pasajes, sobre todo en las secciones referidas a Baudelaire- es el par aura-rastro el que resulta clave a la hora de indagar el siglo XIX. Nuestra hipótesis es que es posible establecer un paralelo entre ambos pares conceptuales.

Palabras clave: alegoría; rastro; tiempo

La salvación se atiene a la pequeña falla en la catástrofe continua. Walter Benjamin, Parque central.

1.

En el Libro de los Pasajes, Benjamin afirma que "[d]e un modo análogo a como el libro sobre el Barroco ilumina el siglo XVII mediante el presente, pero con más claridad, debe ocurrir aquí con el siglo XIX” [N 1 a, 2] $]^{1}$, estableciendo una relación entre éste, su último e inconcluso trabajo, y aquel con el que intentó fallidamente su ingreso a la vida académica.

La simetría de ambos proyectos aparece también documentada en ciertas piezas de su correspondencia personal, principalmente en sus intercambios con Theodor Adorno y Gershom Scholem, en los que Benjamin da cuenta de los avances y las dificultades en la escritura de su proyectada "protohistoria de la modernidad". Así en la carta que dirige a Adorno el 31 de mayo de 1935 en ocasión del envío del primer resumen del Passagenwerk, afirma:

Así como en el libro sobre el Barroco a la exposición de sus fundamentos epistemológicos, le sucedió su confirmación en el material, lo mismo ha de ocurrir en este caso. [...] El exposé ofrece ya indicaciones decisivas sobre los mismos fundamentos [...] Además las analogías con el libro sobre el Barroco aparecen mucho más claras (incluso de una forma sorprendente para mí) que en cualquier estadio anterior del proyecto $^{2}$.

Las analogías a las que Benjamin se refiere, aparecen explicitadas en una carta que algunos días antes había escrito a Scholem, presumiblemente durante el proceso de escritura del exposé "París, capital del siglo XIX":

Por lo demás de vez en cuando cedo a la tentación de imaginar analogías en la construcción interna de este libro con el libro sobre el Barroco, del que se diferenciará mucho externamente. Y quiero mencionarte que, también aquí el desarrollo de un concepto clásico ocupará la posición central. Si allí fue el concepto del Tragedia, aquí lo será el carácter de fetiche de la mercancía. Si el libro sobre el Barroco movilizó su propia teoría del conocimiento, lo mismo ocurrirá, en la misma medida al menos, con los 'Pasajes', aunque no puedo prever si encontraré una exposición independiente o si me saldrá bien. El título de 'Pariser Passagen' ha desaparecido y el borrador se llama 'Paris, die Haupstadt des neunzehnten Jahrhunderts', y para mis adentros se llama 'Paris, capitale du XIX ${ }^{\circ}$ siècle'. Con ello aludo a otra analogía: así como el libro sobre el Drama trata del siglo XVII partiendo de Alemania, este plantea el siglo XIX desde Francia ${ }^{3}$.

La analogías que, según mencionaba Benjamin a Adorno, habían sorprendido al mismo autor, serían según esta carta, además de la relación estructural entre un supuesto epistemológico y su confirmación material, el tipo de tema elegido - un tema clásico, si bien relativo a disciplinas diversas: la tragedia (y también el drama barroco) es un tema 
del repertorio de la crítica literaria, en tanto el carácter de fetiche de la mercancía lo es del materialismo histórico-, y la pretensión de iluminar toda una época a partir del estudio de fenómenos locales.

Queremos aquí proponer otra analogía que Benjamin noha explicitado: así como en el libro sobre el Drama Barroco las categorías de análisis fundamentales son las figuras estéticas del símbolo y la alegoría -y si bien estas categorías perviven en el Libro de los Pasajes, sobre todo en las secciones referidas a Baudelaire- es el par aurarastro el que resulta clave a la hora de indagar el siglo XIX.

Nuestra hipótesis es que es posible establecer un paralelo entre ambos pares conceptuales (símbolo/alegoría y aura/rastro).

La literatura especializada ha prestado mucha menos atención a la Spur benjaminiana que al aura. Es probable que este descuido se deba en parte a que más allá de lo atractivo y productivo del término, en la obra del autor no se encuentra ningún tratamiento sistemático del $\mathrm{mismo}^{4}$, como sí sucede con su correlativo. Intentaremos iluminarlo a partir de la analogía que hemos planteado, desarrollando en primer lugar las categorías estéticas utilizadas por Benjamin para caracterizar el siglo XVII y analizando luego cuál es el lugar que las mismas ocupan en relación al análisis que del siglo XIX intentó el autor. Finalmente, realizaremos el pasaje conceptual desde ellas al par aurarastro, a partir del material del Libro de los Pasajes, el primer exposé y los trabajos sobre Baudelaire. En este punto nos referiremos especialmente a la dimensión temporal tal como la expresa cada uno de los cuatro términos de la analogía planteada: sostendremos también que, tal como sucede con la relación entre símbolo y alegoría en el libro sobre el Drama Barroco, es posible reformular la relación entre rastro y aura a partir de la categoría de tiempo.

\section{El símbolo y la alegoría en el trabajo sobre el Trauerspiel}

En el escrito sobre el Drama Barroco, gestado entre 1916 y 1925, y publicado completo por primera vez en $1928^{5}$, Benjamin definió las figuras estéticas del símbolo y la alegoría en oposición a la categorización que el Romanticismo había hecho de las mismas:

La filosofía del arte lleva más de un siglo sufriendo bajo el dominio de un usurpador que se hizo con el poder bajo la confusión provocada por el Romanticismo. La estética romántica en su búsqueda de un conocimiento deslumbrador (y en definitiva no vinculante) del absoluto, dio carta de naturaleza en las discusiones más elementales de la teoría del arte a un concepto de símbolo que con el genuino no tiene en común más que el nombre ${ }^{6}$.

Según el autor, el concepto de símbolo que reivindica la corriente romántica opera legítimamente en el terreno de la teología, como unidad del objeto sensible y el suprasensible. El Clasicismo, y tras él el Romanticismo, transfieren el símbolo de éste, su ámbito legítimo, al ámbito estético, distorcionándolo al entenderlo como una relación entre manifestación y esencia: el mundo de lo bello y la "noción de inmanencia ilimitada del mundo ético" ", lo moralmente bueno. Afirma Benjamin que 'este abuso tiene lugar siempre que en la obra de arte la 'manifestación' de una 'idea' se considera "símbolo""

Benjamin había desarrollado parte de su crítica a la noción romántica de símbolo algunos años antes en el trabajo sobre Las afinidades electivas de Goethe (1921-1922). Allí, a propósito del destino del personaje de Ottilie en la novela, señala la presencia de un estrato mítico en la obra. Según Benjamin, el arte simbólico al despojar al símbolo de la relación teológica corre el riesgo de recaer en el mito9.

En El origen del Drama Barroco Alemán Benjamin continúa su discusión con Goethe, a partir de una cita en la que este autor ha opuesto el símbolo a la alegoría, describiendo a esta última en términos negativos en relación a aquel. El procedimiento simbólico -consistente en "ver lo general en lo particular"- sería, según Goethe, el propio de la "naturaleza de la poesía", en tanto la alegoría es caracterizada como una búsqueda de lo particular con vistas a lo general.

El concepto de alegoría formulado en términos negativos por el Clasicismo y el Romanticismo, como en la cita de Goethe, no corresponde, según Benjamin, a una auténtica teoría romántica de esta forma de expresión sino que ha sido forjado como "réplica especulativa" del concepto profano de símbolo ${ }^{10} \mathrm{y}$, por lo mismo, resulta una simplificación prejuiciosa que más bien da cuenta de la incomprensión del Romanticismo respecto a la alegoría barroca que de las características propias de ésta última.

El simbolismo profano del Romanticismo hizo propia la figura del "alma bella" en su significación específica de un alma cuya sensibilidad coincide espontánea y plenamente con la ley moral y cuyo mérito consiste simplemente en existir; en este símbolo, la bella apariencia como manifestación se encuentra unida a lo moralmente bueno como esencia en el bello individuo, lo que da cuenta del aspecto individualista de las preocupaciones éticas del arte romántico ${ }^{11}$. Por el contrario, el arte alegórico es el característico del Barroco, un período cuyos problemas de carácter político-religioso afectan no tanto al individuo y su ética sino a su comunidad.

Hay aquí una primer nota diferencial digna de destacarse: en tanto recurso expresivo, el símbolo daría cuenta de la dimensión individual de un tema o conflicto, mientras que en la alegoría se expresaría un conflicto en su dimensión colectiva; las producciones barrocas y en particular el Trauerspiel, toman a la vida histórica de la comunidad, "el curso actual de la historia del mundo" como objeto ${ }^{12}$. Sobre este punto volveremos en breve.

Cadernos Benjaminianos, n. 4, Belo Horizonte, ago.-dez. 2011, página 13-19 
Señala Benjamin que los románticos, y en general los modernos, han supuesto "que la alegoría es una relación convencional entre una imagen designativa y su significado"13, que sirve a la "expresión de un concepto". Contra ello, sostiene que la alegoría no es "un mero modo de designación [...] una técnica gratuita de producción de imágenes, sino expresión, de igual manera que lo es el lenguaje y hasta la escritura" ${ }^{14}$. En el estudio de la forma del Trauerspiel, se propone revelar el movimiento dialéctico que se agita en el hiato abierto entre el ser figurativo y la significación de la alegoría ya que, a diferencia de lo que sucede en el símbolo, figuración y significado no se encuentran interpenetrados. En este sentido afirma en el Libro de los Pasajes:

[El procedimiento barroco] consiste en subordinar el significado a las piezas de la obra, a las partes, procedimiento en el que no tanto se descompone el conjunto cuanto el proceso de su producción. Los emblemas barrocos se pueden entender como productos a medio fabricar que han salido de las fases de un proceso productivo para convertirse en momentos de un proceso destructivo [J 78, 4] $]^{15}$

El arte alegórico se expresa en "representaciones emblemáticas de carácter moral y político"16, composiciones jeroglíficas de imágenes y palabras, en rebus -es decir escritura con imágenes de objetos- y pictogramas. En resumidas cuentas, combina elementos de órdenes diversos y construye una suerte de enigma que debe ser descifrado. Este carácter enigmático y fragmentario de la alegoría constituye un segundo aspecto en que esta figura y el símbolo se oponen:

Es difícil imaginar algo que se oponga más encarnizadamente al símbolo artístico, al símbolo plástico, a la imagen de la totalidad orgánica, que este fragmento amorfo en el que consiste la imagen alegórica [...] En el terreno de la intuición alegórica la imagen es fragmento, runa. Su belleza simbólica se volatiliza [...] . La falsa apariencia de totalidad se extingue. Pues el eidos se apaga, la analogía perece y el cosmos contenido en ella se seca. En los áridos rebus resultantes se encuentra depositada una clarividencia aún accesible al que, confuso, medita rumiando sobre ellos ${ }^{17}$.

Finalmente, señala Benjamin que a la experiencia simbólica corresponde como unidad temporal el "instante místico", en que se accede a la totalidad simbolizada con "claridad [...], brevedad [...], gracia y belleza"18; pero cuando el genuino símbolo teológico da lugar al símbolo profano propio del Romanticismo, el instante místico pierde su carácter divino y se torna afín al mito. En él el paso del tiempo asume la forma de la predeterminación ${ }^{19}$. Según un texto contemporáneo a la redacción de El origen del drama barroco, el tiempo en el mito " es un tiempo no autónomo, que se adhiere parasitariamente al tiempo de una vida superior, menos ligada a la naturaleza. Este tiempo no tiene presente $[. .$.$] y conoce el pasado y el futuro sólo a través de inflexiones características"20.$

En tanto en la alegoría

la historia se muestra a los ojos del observador como paisaje primordial petrificado. Todo lo que la historia tiene desde el principio de intempestivo, de doloroso, de fallido, se plasma en un rostro, o mejor dicho: en una calavera. Y si bien es cierto que esta carece de toda libertad 'simbólica' de expresión, de toda armonía formal clásica, de todo rasgo humano, sin embargo, en esta figura suya (la más sujeta a la naturaleza) se expresa plenamente y como enigma, no sólo la condición de la existencia humana en general, sino también la historicidad biográfica de un individuo. Tal es el núcleo de la visión alegórica ${ }^{21}$.

Es decir que en el centro de la alegoría se encuentra la inscripción de la historia de los padecimientos de la humanidad $^{22}$, que se vuelven particularmente significativos en aquellas épocas signadas por la decadencia y la reflexión melancólica en torno a la muerte, cuya mirada ensombrecida torna significante el devenir de la propia naturaleza. En este sentido, afirma Benjamin que "[e]1 modo mismo de expresión alegórica nació de un peculiar entrecruzamiento entre naturaleza e historia" 23 .

Tenemos entonces tres aspectos fundamentales en que se distinguen el símbolo y la alegoría ${ }^{24}$ : frente al carácter individual de los conflictos expresados en el símbolo, la preocupación colectiva recogida por el arte alegórico; frente a la unidad orgánica propia del primero que acoge en su interior la plenitud del sentido, el carácter fragmentario y enigmático de la segunda; y finalmente, frente a la identificación instantánea con la eternidad (mística o mítica según sea su carácter teológico o del profano) del símbolo, la historicidad inscripta en el centro de la alegoría. Es importante señalar que todos los aspectos característicos de la alegoría son recogidos por Benjamin en su propuesta de historiografía crítica desarrollada en los legajos específicos del Libro de los Pasajes ${ }^{25}$.

\subsection{La alegoría en la protohistoria de la Modernidad. Baudelaire.}

Como ya hemos señalado, en los trabajos que Benjamin desarrolló desde mediados de la década del '20 y hasta el final de su vida y que tuvieron por tema la protohistoria de la modernidad, la categoría de alegoría permanece restringida al ámbito estético -y más específicamente literario- en tanto el objeto de estudio se amplía. Por lo mismo, si bien Benjamin no la deja totalmente de lado, su aplicación se limita a la investigación sobre Baudelaire, cuya heroica tarea, afirma, consistió en dar forma a la modernidad ${ }^{26}$ y en cuya obra, que considera "la obra poética del siglo", la en apariencia "inactual" alegoría ocupa un lugar central ${ }^{27}$. 
En estos estudios específicos ${ }^{28}$, Benjamin incorpora a la figura del alegorista el "comportamiento alegórico" que, a diferencia del "temperamento" que le correspondía en el libro sobre el Barroco caracterizado sólo por su melancolía, incluye ahora en el retrato del poeta del siglo XIX el "instinto destructivo"29: "Arrancar los objetos de sus relaciones habituales [...] es un procedimiento altamente característico en Baudelaire; está vinculado en la intención alegórica a la destrucción de las relaciones orgánicas" 30 .

En contraposición a la alegoría barroca, la alegoría baudelairiana incorpora los rasgos de un profundo rencor. Es éste el que mueve al alegorista a producir imágenes que conviertan en ruinas las configuraciones armónicas del mundo ${ }^{31}$ : "La alegoría de Baudelaire lleva el rastro de la violenta actividad que fue precisa para derribar la armónica fachada del mundo que le rodeaba" [J 55a, 3]; por ello, "[e]n tanto la alegoría barroca sólo ve el cadáver por fuera, Baudelaire lo hace presente desde adentro" [J 56, 2$]^{32}$.

Por otro lado, además de este carácter activamente destructivo del poeta de la modernidad, a diferencia de la alegoría propia del barroco, la alegoría de Baudelaire se dirige no sólo contra el mito ${ }^{33}$, sino intencionalmente también contra el aura -lo cual sugiere que también entre mito y aura hay una fuerte conexión-. Si bien Benjamin sospechaba que en general "las épocas que se inclinan a la expresión alegórica han experimentado una crisis del aura" $\left[\mathrm{J} 77^{\mathrm{a}}, 8\right]^{34}$, en el caso de Baudelaire el provocar esta crisis tendría en su lírica un carácter casi programático; en este sentido resulta clave la lectura que realiza del poema "Pérdida de la aureola" de Las flores del mal. Según Benjamin el poeta ha puesto la figura de la alegoría al servicio del ocaso del aura ${ }^{35}$.

De esta noción que, según nuestra hipótesis inicial puede relacionarse con la de "símbolo" operante en el trabajo sobre el Trauerspiel, en el célebre texto sobre La obra de arte, Benjamin ofrece una también célebre definición. Según ella, el aura sería la "manifestación irrepetible de una lejanía (por cercana que pueda estar)"36; en otros pasajes se la define como la proyección sobre los objetos de una experiencia entre seres humanos: es como si la mirada que sobre ellos se posa fuese respondida ${ }^{37}$. En todo caso la experiencia aurática consiste en el perderse del espectador en la contemplación, su sumergirse en ella ${ }^{38}$. En el caso de la obra de arte, este tipo de experiencia, que se deriva de la función cultual del arte en sus orígenes, pervive en la actualidad en el "halo" que rodea las obras "originales" y se encamina hacia su liquidación a partir de la reproducción técnica de las obras artísticas y de la vivencia de shock [J $64 a, 1]^{39}$-aspectos ambos que son recogidos y sintetizados por el procedimiento del montaje-. Así, el aura resulta afín al símbolo, en tanto éste "atrae hacia sí al hombre", es decir tal como el aura tiende a absorverlo. ${ }^{40}$

En su segundo ensayo sobre Baudelaire, Benjamin describe al poeta como "traumatófilo": la tarea que ordena la producción poética baudeleriana ha consistido en hacer "asunto propio parar con su persona espiritual y física los shocks, cualquiera que fuese su procedencia"41 a fin de recoger como experiencia esta vivencia central de la modernidad que deriva en la liquidación de la experiencia aurática, oponiendo a su silencio el ruido de París inserto rítmicamente en sus versos ${ }^{42}$. Por eso, "[1]a renuncia a la magia de la lejanía es un momento crucial de la lírica de Baudelaire" 43 .

Como hemos mencionado, Benjamin señala que es contra el aura que Baudelaire ha dirigido su "impulso destructivo", contrarrestando la tendencia a la absorción con sus invectivas alegóricas, que encierran "ante todo una profunda protesta contra lo 'orgánico"" 44 y haciendo énfasis en lo fragmentario de la obra de arte. Sin embargo, afirma también que, a diferencia de la visión alegórica barroca, la del siglo XIX no generó un estilo; Baudelaire estaba, como alegorista, aislado. Así como su impulso alegórico sigue estando restringido al ámbito estético-literario.

\subsection{Fetiche y ruina -o aura y rastro- en el Libro de los Pasajes}

Para abordar el tema propuesto como central para iluminar la protohistoria de la modernidad, es decir la mercancía, Benjamin distingue en ella un doble carácter: el de fetiche y el de ruina. O, como escribe en el exposé de 1935, entre su elemento utópico y su elemento cínico ${ }^{45}$.

En las exposiciones universales es el primer carácter -fantasmagórico- el entronizado En ellas, la mercancía es venerada en tanto fetiche según el ritual prescripto por la moda ${ }^{46}$, allí lo nuevo aparece como independiente del valor de uso de la mercancía, y se vuelve

el origen de ese halo intransferible de las imágenes que produce el inconsciente colectivo. Es la quintaesencia de la conciencia falsa cuyo incansable agente es la moda. Este halo de lo nuevo se refleja, tal un espejo en otro, en el halo de lo siempre-otra-vez-igual. El producto de esta reflexión es la fantasmagoría de la 'historia de la cultura' en que la burguesía paladea su falsa conciencia ${ }^{47}$.

En tanto fetiche, entonces, la mercancía se encuentra auratizada, encantada; por el contrario, en su carácter de ruina puede leerse en ella el rastro de la historia.

Ya en El origen del drama barroco, Benjamin había afirmado que "Las alegorías son en el reino del pensamiento lo que las ruinas en el reino de las cosas"48; y en Zentralpark afirma que "La devaluación del mundo de los objetos en la alegoría es propasada, dentro del mismo mundo de los objetos, por la mercancía" ${ }^{49}$; por eso, la mercancía toma en su estudio del siglo XIX el lugar de la contemplación alegórica ${ }^{50}$; esto sólo puede hacerlo en su carácter de ruina, intrincado en el fetiche como los elementos ctónicos y construcciones de épocas diversas en la ciudad moderna donde aparecen como rastros a los ojos del flaneur ${ }^{51}$. Es en este sentido que Benjamin se propone interrogar las

Cadernos Benjaminianos, n. 4, Belo Horizonte, ago.-dez. 2011, página 13-19 
producciones culturales del sigo XIX: ellas conservan en sí los rastros de la historia, que al hacerse evidentes por obra del historiador materialista las desencantan dejando al descubierto su carácter ruinoso, y es a partir del descubrimiento de esta "falla" que constituye el rastro que es posible la salvación de los fenómenos de la catástorfe histórica contenida en la idea de progreso ${ }^{52}$.

La mirada del historiador materialista debe dirigirse entonces, tal como la del detective, o el alegorista (figuras ambas que en el Libro de los Pasajes encarna Baudelaire, en un caso como "rezagado", en el otro como "prefigurador") a aquellos rastros temporales que, imbricadas en las producciones artísticas y culturales del siglo XIX, dan cuenta de la historicidad de las mismas. Esta mirada alegórica, desmitificadora ${ }^{53}$, despierta, como si se tratara de algo que ha sido soñado, un "saber aún no conciente de lo que ha sido", promoviendo el despertar colectivo del gran sueño epocal en que el propio tiempo se halla inmerso.

El rastro, como lo alegórico "irrumpiendo desde las profundidades del ser, intercepta la intención en su camino descendente y la golpea en el rostro" 54 , impide el abismarse del espectador en la cosa. En arquitecturas, publicidades, monumentos e imágenes del siglo XIX "la historia ha quedado reducida a una presencia perceptible" 55 , ha dejado allí su rastro.

Podemos señalar entonces en relación a los pares conceptuales símbolo/alegoría y aura/rastro varias similitudes: también en este par el primero de los términos remitiría a una experiencia en que la aparición de la cosa suspendería la historia: la moda y la mercancía como fetiche "auratizado" oculta tras la apariencia de "novedad" la emergencia de lo-siempre-otra-vez-igual, imágenes de la conciencia colectiva en que lo nuevo se interpenetra con lo viejo ${ }^{56}$, y que, como los arquetipos míticos jungianos impedirían la acción eficaz del sujeto en el presente ${ }^{57}$. En el terreno de las producciones estéticas, tal como el símbolo, el aura promueve el éxtasis individual del espectador que se sumerge en la obra de arte, y, como el símbolo también restituye la apariencia de unidad orgánica contra la que eleva su protesta la alegoría baudeleriana. En tanto el rastro inscribe la historia en el seno de las producciones culturales, permite por lo mismo el aprovechamiento en términos colectivos de los sueños utópicos que en ellas yacen, disolviendo su falsa unidad y presentándolas como escombros, fragmentos que el historiador materialista habrá de ensamblar de nuevo. El montaje, en tanto procedimiento "estilístico" -en el sentido privilegiado que tiene el término en el texto sobre el Drama Barroco ${ }^{58}$ - actualiza y rescata del olvido los fenómenos del pasado al quedar las diversas épocas afectadas por el presente del historiador ${ }^{59}$. Por eso aparece en la Spur "una cercanía, por lejos que pueda estar lo que la dejó atrás"; en ella "nos hacemos con la cosa; [mientras que] en el aura es ella [la cosa] la que se apodera de nosotros" [M16a, $4]^{60}$

A diferencia del símbolo y la alegoría, que en sí mismos y en tanto procedimientos estilísticos, construyen objetos diferentes, el aura y el rastro pertenecen como aspectos contradictorios al mismo objeto (la mercancía). Así será la mirada de alegorista -o de detective- del historiador la que detectará la falla temporal -el rastro- a partir de la cual podrá quebrar la apariencia aurática.

En el libro sobre el Barroco Benjamin afirmaba que "[1]a relación entre el simbolo y la alegoría se puede definir y formular persuasivamente a la luz de la decisiva categoría del tiempo"61. Según creemos esta misma categoría fundamental serviría para reformular la relación entre rastro y aura: el rastro sería, en sí mismo, un índice de su tiempo, aquello que "arruina" la unidad orgánica de las fantasmagorías del siglo XIX, la pequeña falla de la cual es posible aferrarse y que permite entonces al autor interrogar e interpretar las producciones culturales de un modo productivo para el historiador materialista, que deberá proceder con ellos como un arqueólogo, o también como un psicoanalista frente a formaciones oníricas colectivas, reconociendo en ellas los fragmentos de deseos e incumplidas promesas de felicidad, para salvarlas así de la catástrofe.

\section{Referencias Bibliográficas:}

ADORNO, Theodor/BENJAMIN, Walter, Correspondencia 1928-1940, ed. Henri Lonitz, trad. Jacobo Muñoz Veiga y Vicente Gómez Ibáñez, Madrid, Trotta, 1998.

BENJAMIN, Walter, "Destino y carácter" (1919), en: -, Ensayos escogidos, trad. H. A. Murena, México, Ediciones Coyoacán, 2001

BENJAMIN, Walter, El origen del drama barroco alemán, trad. José Muñoz Millanes. Madrid: Taurus, 1990.

BENJAMIN, Walter, "La obra de arte en la época de su reproductibilidad técnica". En: -, Discursos interrumpidos, trad. Jesús Aguirre, Buenos Aires, Taurus, 1989

BENJAMIN, Walter, "Las afinidades electivas de Gorthe". En: -, Dos ensayos sobre Goethe, trad. Graciela Calderón y Griselda Mársico, Barcelona, Gedisa, 1996

BENJAMIN, Walter, Libro de los Pasajes, ed. Rolf Tiedemann, trad. Luis Fernández Castañeda (alemán y textos en inglés), Isidro Herrera (francés menos los fragmentos $\mathrm{J}$ y N) y Fernando Guerrero (textos en francés de los fragmentos J y N). Madrid: Akal, 2005.

BENJAMIN, Walter, "París, capital del siglo XIX", en: -, Poesía y capitalismo. Iluminaciones II, trad. Jesús Aguirre, Madrid, Taurus, 1998.

BENJAMIN, Walter, Parque central, trad. Ronald Kay. Santiago, Ediciones Metales pesados, 2005. 
BENJAMIN, Walter, “Sobre algunos temas en Baudelaire”, En: -, Poesía y capitalismo. Iluminaciones II, trad. Jesús Aguirre, Madrid, Taurus, 1998.

BENJAMIN, Walter /SCHOLEM, Gershom, Correspondencia 1933-1940, ed Gershom Scolem, trad. Rafael Lupiani, Madrid, Taurus, 1987.

BUCK-MORSS, Susan, Dialéctica de la mirada. Walter Benjamin y el proyecto de los Pasajes, trad. Nora Rabotnikof, Madrid, Visor, 2001.

CASTEL, María, "Temporalidad inconsciente y tiempo histórico. Acerca de la recepción benjaminiana de la obra de Sigmund Freud”, en: ACHA, O. /VALLEJO, M. (editores), Inconsciente e historia después de Freud. Cruces entre filosofía, psicoanálisis e historiografía, Buenos Aires, Prometeo 2010.

GAGNEBIN, Jeanne Marie, Geschichte und Erzählung bei Walter Benjamin, Würzburg, Königshausen \& Neumann, 2001.

KRAMER, Sven, Walter Benjamin zur Einführung, Hamburg : JUNIUS-Verl., 2003.

MENKE, Bettine, "Ursprung des deutschen Trauerspiel", en LIDNER, B. (ed.), Benjamins Handbuch. Leben-WerkWirkung, Stuutgart-Weimar, Metzler, 2006.

\section{Notas:}

${ }^{1}$ BENJAMIN, W., Libro de los Pasajes, p. 461.

2 ADORNO, Th./BENJAMIN, W. , Correspondencia 1928-1940, p. 98.

3 BENJAMIN, W./SCHOLEM, G., Correspondencia 1933-1940, p. 178. La cita corresponde a la carta del 20 de mayo de 1935.

${ }^{4}$ El legajo I del Libro de los Pasajes lleva por título "El interior, el rastro", sin embargo no hay en él una caracterización explícita de lo que Benjamin entiende bajo esta denominación; la noción de rastro se pone allí en relación al interior burgués, a la novela detectivesca y al surgimiento de la burocracia administrativa, todos ellos fenómenos netamente modernos. Por otro lado, la misma noción aparecía referida en la primer versión del exposé, allí en el cuarto apartado ("Luis Felipe o el interior") afirma que "[h] abitar es dejar rastros". Dicho apartado y esta fórmula en particular es rescatada y celebrada por Adorno en su comentario por lo demás eminentemente crítico al texto (Cfr. ADORNO, Th. / BENJAMIN, W., Op Cit., p. 112).

${ }^{5}$ Cfr. MENKE, B., "Ursprung des deutschen Trauerspiel", p. 210.

${ }^{6}$ BENJAMIN, W., El origen del drama barroco alemán, p. 151.

${ }^{7}$ IDEM, p. 152. Sobre este punto coincidimos con Jeanne Marie Gagnebin cuando subraya que Benjamin "no rechaza el símbolo en cuanto tal, sino que condena tan sólo su reducción a la simple relación entre manifestación y esencia" - GAGNEBIN, J. M., Geschichte und Erzählung bei Walter Benjamin, Würzburg, Königshausen \& Neumann, 2001, p.40 - trad. propia.

${ }^{8}$ BENJAMIN, W., El origen del drama barroco alemán, p. 152.

${ }^{9}$ Este señalamiento es el tema de la primera de las tres partes del escrito de Benjamin, cuyo manuscrito de trabajo consigna bajo el subtítulo de "Lo mítico como tesis"; los correspondientes a las otras dos secciones son: "La salvación como antítesis" y "La esperanza como síntesis". Estos subtítulos no aparecen en las ediciones impresas por expresa indicación del autor. Cfr. los "Comentarios a "Las afinidades electivas de Goethe" en : BENJAMIN, W., Dos ensayos sobre Goethe, p. 113. Por otro lado, la figura de Ottilie es caracterizado una y otra vez en la novela goethiana como puramente "bella", caracterización que al no completarse con ningún rasgo de naturaleza moral la convertiría en la lectura de Benjamin en una figura mítico-simbólica. Al respecto dice en su estudio: "[En la existencia de Ottilie] la belleza sigue siendo lo primero y esencial [...] siempre se invoca sólo una apariencia, la belleza viva en Ottilie, que se imponía con fuerza, enigmática y no purificada, como 'materia' en el sentido más poderoso. Así se confirma el carácter propio del Hades que el poeta confiere a los acontecimientos" - BENJAMIN, W., "Las afinidades electivas de Gorthe", pp. 76s.

${ }^{10}$ BENJAMIN, W., El origen del drama barroco alemán, p. 153.

${ }^{11}$ IDEM, p. 152.

${ }^{12}$ Cfr. IDEM, pp. $47 \mathrm{~s}$.

${ }^{13}$ IDEM, pp. $154 \mathrm{~s}$.

${ }^{14}$ IDEM, p. 155.

${ }^{15}$ BENJAMIN, W., Libro de los Pasajes, p. 372.

${ }^{16}$ BENJAMIN, W., El origen del drama barroco alemán, p. 47.

${ }^{17}$ IDEM, pp. $168 \mathrm{~s}$.

${ }^{18}$ IDEM, p. 156.

${ }^{19}$ Cfr. BUCK-MORSS, S., Dialéctica de la mirada. Walter Benjamin y el proyecto de los Pasajes, p. 95.

${ }^{20}$ BENJAMIN, W., "Destino y carácter" (1919), p. 135.

${ }^{21}$ BENJAMIN, W., El origen del drama barroco alemán, p. 159. El destacado es nuestro.

22 En el segundo capítulo de su estudio, J. M.Gagnebin afirma en este sentido que "[1]a interpretación alegórica verdadera 'escritura del desastre'- es profundamente historica, lo que para Benjamin en este momento de su desarrollo significa, crítica de toda visión mítica que, como en Goethe o incluso en los románticos tempranos, arraiga aún el sentido de la historia en el paradigma la organicidad natural" -GAGNEBIN, J. M., Op. Cit., p. 49 - trad. propia.

${ }^{23}$ IDEM, p. 160.

${ }^{24}$ J. M. Gagnebin sintetiza la comparación entre el símbolo y la alegoría del siguiente modo: "Mientras el símbolo apunta hacia la eternidad de la belleza, la alegoría pone de relieve la imposibilidad de un sentido eterno y la necesidad 
de perseverar en la temporalidad y la historicidad para fundar significaciones transitorias. Mientras el símbolo, como su nombre lo indica, aspira a la unidad del ser y la palabra, la alegoría insiste en su no identidad esencial, porque el lenguaje siempre dice algo distinto (allo-agorein) que aquello a lo que refiere, porque surge y vuelve a surgir solamente de esa eterna huida de un sentido último" (GAGNEBIN, J. M. , Op. Cit., p. 43 - trad. propia) olvida así en su caracterización el aspecto colectivo que reviste la alegoría frente al símbolo. Este rasgo nos parece sin embargo central, ya que recoge lo que en escritos posteriores aparecerá como una preocupación fundamental de Benjamin. Así, será este uno de los puntos en los que el autor tomará distancia de una concepción por lo demás tan afín a su pensamiento como la de la memoria involuntaria elaborada por Bergson en Materia y memoria y retomada por Proust en En busca del tiempo perdido (Cfr. BENJAMIN, W., "Sobre algunos temas en Baudelaire", p. 128)

${ }^{25}$ Nos referimos especialmente a los legajos $\mathrm{K}$ y $\mathrm{N}$ de la obra.

${ }^{26}$ Cfr. el fragmento J 51a, 7 del Libro de los Pasajes, p. 330.

27 BENJAMIN, W., Parque central, p. 28. Conviene sin embargo señalar que Baudelaire no utiliza únicamente la alegoría, sino también el símbolo. Esta dualidad se manifestaría inclusive en la fórmula "Spleen e Ideal" con la que titula el primer libro de Las flores del mal: "El ideal remite a la armonía perdida que la palabra poética busca evocar, armonía entre el lenguaje de la naturaleza y el lenguaje del hombre, armonía de los diferentes sentidos entre ellos, entre el espíritu y la sensibilidad, como declara el soneto de las Correspondencias. En este paisaje ideal, que despierta el deseo de una fusión originaria, el tiempo ya no pasa, sino que se sociega en el ritmo regular de las olas marinas una apreciada imagen de Baudelaire para la felicidad. Pero existe el otro tiempo, el del Spleen (¡un muy moderno anglicismo!) el tiempo hostil que devora la vida, descompone cada instante de felicidad, cada visión de belleza y acaba por destruir al poeta" - GAGNEBIN, J. M., Op. Cit., p. 56 - trad. propia. Respecto a este carácter ambiguo del poeta, Benjamin señala que "Baudelaire tiene que agradecer al genio de la alegoría no haber caído en el abismo del mito, que lo acompañó siempre en su camino" [J 22, 5] - BENJAMIN, W., Libro de los Pasajes, p. 281.

${ }^{28}$ Nos referimos al material "crudo" del legajo J del Libro de los Pasajes, a los resúmenes (exposés) que Benjamin elaboró para el Instituto de Investigación Social, a los fragmentos reunidos bajo el título Zentralpark y a su segundo ensayo sobre Baudelaire, de 1939.

${ }^{29}$ BENJAMIN, W., Parque central, p.20.

${ }^{30}$ IDEM, p. 21

${ }^{31}$ IDEM, p.22.

32 BENJAMIN, W., Libro de los Pasajes, pp. 336s.

${ }^{33}$ BENJAMIN, W., Parque central, pp. 28 y 31.

${ }^{34}$ BENJAMIN, W., Libro de los Pasajes, pp. 371s.

${ }^{35}$ BENJAMIN, W., Parque central, p.21.

${ }^{36}$ BENJAMIN, W., "La obra de arte en la época de su reproductibilidad técnica", p. 24.

${ }^{37}$ Cfr. BENJAMIN, W., Parque central, ed. cit., p. 21; también "Sobre algunos temas en Baudelaire", p. 163.

${ }^{38}$ BENJAMIN, W., "La obra de arte en la época de su reproductibilidad técnica", p. 53.

${ }^{39}$ BENJAMIN, W., Libro de los Pasajes, p. 350.

${ }^{40}$ Cfr. BENJAMIN, W., El origen del drama barroco alemán, p. 177 y el fragmento M 16a, 4 del Libro de los Pasajes, p. 450.

${ }^{41}$ BENJAMIN, W., "Sobre algunos temas en Baudelaire", p. 133.

${ }^{42}$ BENJAMIN, W., Parque central, p. 30.

${ }^{43}$ IDEM, p. 21

${ }^{44}$ IDEM, p. 27.

${ }^{45}$ BENJAMIN, W., "París, capital del siglo XIX", p. 180.

${ }^{46}$ IBIDEM.

${ }^{47}$ IDEM, p. 186.

${ }^{48}$ BENJAMIN, W., El origen del drama barroco alemán, p. 171.

${ }^{49}$ BENJAMIN, W., Parque central, p. 11.

${ }^{50}$ IDEM, p. 38.

${ }^{51}$ BENJAMIN, W., "París, capital del siglo XIX", p. 171.

52 BENJAMIN, W., Parque central, p. 35.

${ }^{53}$ IDEM, p. 28.

${ }^{54}$ BENJAMIN, W., El origen del drama barroco alemán, p. 177.

${ }^{55}$ IDEM, p. 171.

${ }^{56}$ Cfr. BENJAMIN, W., "París, capital del siglo XIX", p. 175.

${ }^{57}$ Cfr. CASTEL, M., "Temporalidad inconsciente y tiempo histórico. Acerca de la recepción benjaminiana de la obra de Sigmund Freud", pp. 59ss.

${ }^{58}$ Cfr. BENJAMIN, W., El origen del drama barroco alemán, ed. cit., pp. 14s.

${ }^{59}$ Cfr. el fragmento N 7a, 2 del Libro de los Pasajes, p. 473.

${ }^{60}$ BENJAMIN, W., Libro de los Pasajes, p. 450.

${ }^{61}$ BENJAMIN, W., El origen del drama barroco alemán, p. 158. 